\section{Neurotic Disorder}

Chris Loftis

National Council for Community Behavioral

Healthcare, Alexandria, VA, USA

\section{Synonyms}

Neurosis; Neurotic; Neuroticism

\section{Definition}

A mental disorder that causes persistent distress. It is an older term used to describe nonpsychotic mental disturbances characterized by symptoms of anxiety, insecurity, phobias, or depression. Symptoms impair functioning, but individuals have intact reality testing, no violations of gross social norms, and no apparent biologically based etiology. Social relationships may be greatly affected but usually remain within acceptable limits. Once a common psychiatric diagnosis, the term is now regarded as lacking in objectivity and is no longer part of the mainstream psychiatric terminology. Although it is not defined by the DSM-V, it is employed in psychoanalytic theory and practice where the term is used to describe a class of disorders triggered by unconscious defense mechanisms for unresolved conflicts.

\section{Cross-References}

Neurotic Personality

\section{References and Readings}

American Psychiatric Association. (2013). Diagnostic and statistical manual of mental disorders (5th ed.). Washington, DC: American Psychiatric Association.

Russon, J. (2003). Human experience: Philosophy, neurosis, and the elements of everyday life. Albany: State University of New York Press. 